\title{
Editorial
}

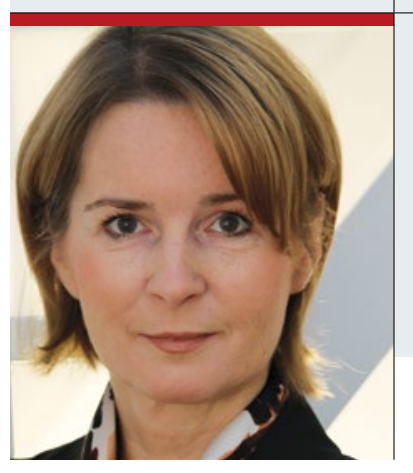

Katja Kupfer-Geißler

Chefredaktion

katja.kupfer@springer.com

facebook.com/springerpflege

\section{Inne halten}

$\mathrm{M}$ ein Konfirmandenunterricht ist zwar auch schon einige Jahrzehnte her, aber ein Foto und die anschließende Diskussion darüber sind mir besonders im Gedächtnis geblieben: Das Bild, das wir uns im Unterricht ansahen, zeigte ein OP-Team, das mit gefalteten Händen im Operationssaal stand. Verdutzte Gesichter unter uns 13-Jährigen: Beten die etwa vor der OP? Warum eigentlich nicht? Manche OP ist doch ein Risiko, da geht es vielleicht um Leben und Tod. So überlegten wir eine Weile hin und her, bis wir die Auflösung erhielten. Das vermeintliche Gebet entpuppte sich als ein übliches Vorgehen im OP zur Vermeidung von Hygienefehlern.

Dennoch: Schon damals sprachen wir über ethische Prinzipien, hatten abgewogen und uns Szenarien vorgestellt, in denen ein Gebet oder ein kurzes Innehalten gar nicht so abwegig sein könnten. Es ist eine Diskussion, die nicht abreißt. Trotz gesetzlicher Regelungen, Richtlinien oder Patientenverfügungen - immer wieder stoßen Menschen an die Gren- zen ihrer Handlungsmöglichkeiten oder geraten in Konflikt mit ihren ethischen Grundsätzen - auch Mediziner, Pflegekräfte und Angehörige, wenn es um den anvertrauten Patienten oder geliebten Menschen geht. In unserem PflegeKolleg „Ethik für Pflegende" (Seite 29) haben wir die Diskussion aufgenommen. Alle drei Autoren, zwischen Altenpflege und ITS, sprechen sich darin für eine ethische Fallbesprechung aus. Sie dient der Reflexion und ermöglicht, Lösungen zu finden, die für alle - therapeutisches Team, Angehörige und Patient - tragbar sind.

\section{Viel Spaß beim Fortbilden mit HEILBERUFE} Ihre

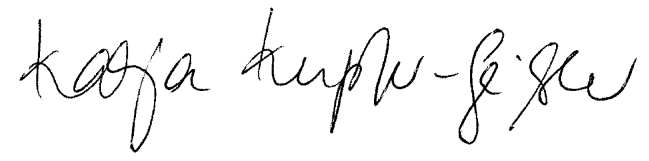

Anregungen, Wünsche, Fragen oder Lob?

Schreiben Sie uns: katja.kupfer@springer.com

\section{NEUE AUSSTELLUNG}

\section{Dem Verbrechen auf der Spur}

Für Krimi-Fans ist die Ausstellung Hieb § Stich ein Muss! Rekonstruierte Tatorte, kriminaltechnische Maßnahmen zur Spurensicherung und dokumentarische Fotografien realer Tatorte in Berlin zeigen den Alltag von Rechtsmedizinern und Kriminaltechnikern. Das Berliner Medizinhistorische Museum der Charité (BMM) gewährt außerdem Einblicke in Methoden und Techniken der systematischen Spurenauswertung, wie Genomanalyse, Insektenkunde oder modernste radiologische Möglichkeiten der 3D-Rekonstruktionen. Vorträge und Lesungen mit prominenten Wissenschaftlern wie Prof. Dr. Michael Tsokos oder Dr. Mark Benecke ergänzen die Ausstellung, die noch bis zum 14. Januar 2018 zu sehen ist.

www.bmm-charite.de

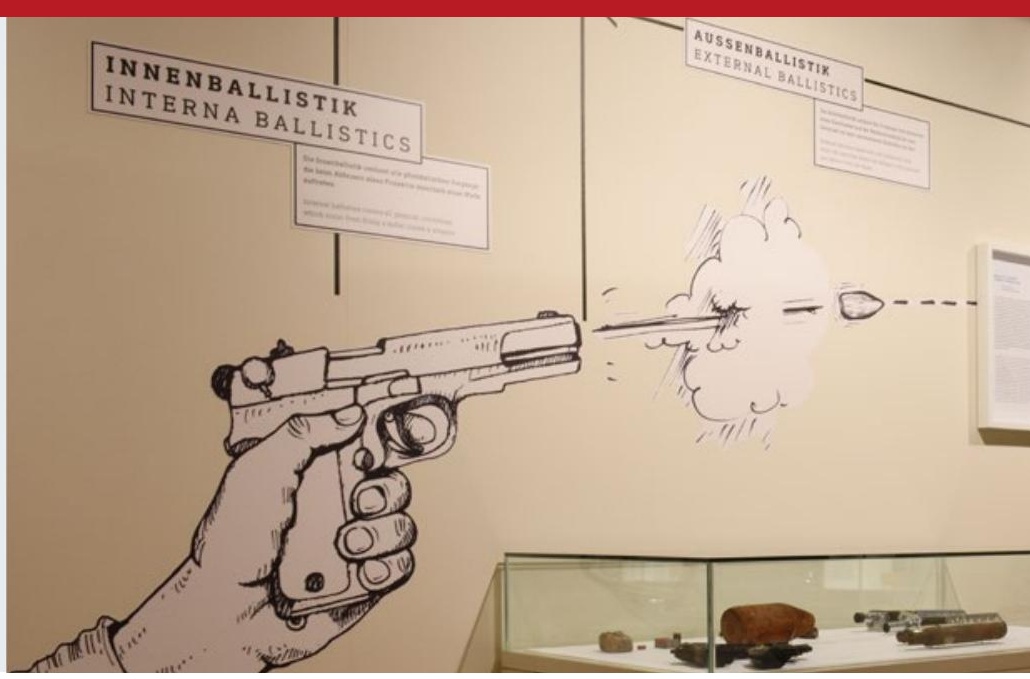

